\title{
Embedding Stock Tracking Module into Elec- tronic Fiscal Device Machine and its Manage- ment System to Reduce Tax Evasion: A case of Tanzania
}

\author{
Paul E. Shao \\ The Nelson Mandela African Institution of Science and Technology, P. O. Box 447, Arusha, Tanzania \\ Mwenge Catholic University, P. O. Box 1226, Moshi, Tanzania \\ Email: shaop@nm-aist.ac.tz or shaopaultz@gmail.com \\ Dr. Mussa Ally Dida \\ The Nelson Mandela Institution of Science and Technology, PO Box 447 Arusha, Tanzania \\ Email: mussa.ally@nm-aist.ac.tz
}

Received: 05 July 2019; Accepted: 24 July 2019; Published: 08 September 2019

\begin{abstract}
The Electronic Fiscal Device (EFD) Machines have been operating in Tanzania since the year 2010 for the purpose of helping the Tanzania Revenue Authority (TRA) to increase revenues from tax collection. Regardless of years of its existence, there are still reported cases of tax evasion, and this study was conducted to review the current tax collection system and analyze requirements for the development of Stock Tracking Module (STM) to be embedded in the current tax collection system. This paper earmarked some problems relating to Electronic Fiscal Device Machine Management System (EFDMS) and EFD machine. Data collection was done in Kilimanjaro and Arusha, the two regions of Tanzania that involved tax officers and Information Technology (IT) personnel from TRA and drug traders. Data collection process involved both qualitative and quantitative methods to gather data for the development of the system Stock Tracking Module (STM) such as interview, questionnaire, role-playing and observation. The major findings of the study: The efficiency of the EFDMS is at average, thus, need some improvements. The major problems encountered by TRA are; under declaration of sales by traders, non-usage of EFD machines, usage of fake EFD, overestimate of expenses, division of business and conducting business in unknown areas. The proposed solution will reduce the existing challenges and increase revenue collections, reduce manual work and human resource, and improve accuracy on tax estimation process.
\end{abstract}

Index Terms - Tax Evasion, EFD machine, Electronic Fiscal Device Management System (EFDMS), Stock Tracking Module (STM), and Tanzania Revenue Authority (TRA).

\section{INTRODUCTION}

Tax evasion is considered to be the major cause of financial fatigue that most governments are facing nowadays (1). With the increase of the Information Communication Technology (ICT) use in recent years, significant number of nations have adopted ICT tools to combat the problem of tax evasion in different areas of trading whereby Accounting Systems (AS) and e-government systems are designed and/or integrated for the purpose of collecting, storing and auditing of tax-related information (2).

Electronic Fiscal Devices (popularly known as EFD machine in Tanzania), Electronic Cash Register (ECR), computer-based point of sales systems (POS), or those that are tablet or smartphone-based have proven to be efficient ICT tools to many countries in improving tax collection that include Income, Corporate, Service levy, and Value Added Taxes (3)

According to the Organization for Economic Cooperation and Development (3) whose its 27 member countries are using such systems, revenues from tax had increased. Particularly in Hungary, Australia, Belgium, Canada, and Sweden, revenues from tax has increased at an average of $8 \%$ per annum. The use of EFD machines to combat tax evasion among East African countries that include Tanzania, Kenya, Rwanda, Uganda, and Burundi proved to be successful such that in Rwanda between year 2013 and 2015 revenues had increased by $20 \%$ annually(3), while in Kenya between year 2000 and 2005 tax collections had increased at rate of 5\% per annum (4). 
In 2010, Tanzanian government geared a parliamentary act and finance act that fostered to the adoption of EFD machines by businessmen across the country for the purpose of dealing with the problem of tax evasion in the trading arena (5). Upon the introduction of the devices, it was observed that the operations of EFD machines had eventually increased the number of government revenues raised from Income, Corporate, Service Levy and Value Added tax (6).

Although TRA has presented EFD machines to traders that eventually improved tax collections, but falsification of taxation still exists due to difficulties of monitoring the use of those machines whereby various techniques that appear to popularly being used by some traders being; trading without issuing receipts, issuing underpriced receipts, and as well, the existence of fake EFDMS (7). Even though falsification of information that leads to underpayment of tax is an offense that results in imprisonment or fine but still there are reported cases of tax evasion(8). It is clear that the use of EFD machines to Tanzania governments is not a single fix solution to tax evasion, but nations that were able to implement it effectively, substantial achievements speaks for themselves.

A case in point, in Tanzania, the current EFDMS can neither detect nor identify traders who trade without issuing a receipt, falsifying sales value nor did issue forged receipts. While EFD machines and EFDMS can be incorporated with STM to keep track of stock flow from manufacturers to whole sellers and trickle it down all the way to retailers so that TRA can have information about the amount of stock owned and sold by a trader, it is not yet that way. Therefore, this paper unleashes an on-going study that aims at incorporating STM to both EFD machines and EFDMS for the purpose of detecting tax evaders. The aim of this study is to analyze the requirements for the development of STM that will alert TRA of the falsification of sales value, forged receipts and transactions took place without issuing a receipt.

The paper consists of six sections: Section One outlines the problem background and problem statement. Section Two entails the review of the related works. Section Three presents data collection methods, sample size, and sampling techniques. Section Four describes the current system, proposed system, database schema, and EFD App design. On the other hand, section Five discusses the findings of the research while section Six contains conclusion and future work.

\section{RELATED WORKS}

Following the adoption of EFD machines as a tool for tax collection around the global, significant number of governments have increased their revenue collections raised from taxes. The main goal of adopting EFD machines by revenue authorities is to have proper business records keeping, easing the process of tax estimation, and improving information flow from traders to revenue authorities and vice versa.

(9) Presented a study that analyzes challenges that hinder EFD machine implementation in Tanzania. The chal- lenges include: lack of education, system breakdown, and commodities underpricing. The study further discussed solutions that could be implemented by the authority to reduce the grief, in such ways as stakeholder's awareness and friendly operating environment; however, the researcher didn't discuss the technological weakness of the system and solutions to bring down the case.

The study done by (6) on the effectiveness of EFD implementation in Tanzania, shows that the problem of tax evasion exist among EFD machine users whereby the scholar identifies the high cost of buying EFD device as the main reason for the lack of support from business operators. Furthermore, the researchers suggest that educational programs and increase of EFD machine rollouts in the country was a good ways for pursuing the reduction of tax evasion, but however, the study does not address the EFD Management System and EFD machine gaps that encourage traders to evade tax without being detected.

According to (10) in a publication on challenges facing the adoption of EFD machines in Tanzania, indicates that, TRA is facing communication constraints, claiming of false VAT returns, lacking culture of requesting financial receipts, issue of monetary receipt to fewer deals than actual, and opposing the procurement and utilization of EFD machines as the major challenges. In spite of the study being among the few studies backing up the revenue authority, but EFD Management System weaknesses were not discussed.

In Ethiopia, EFD machines were adopted by Ethiopia Revenue and Customs Authority (ERCA) since 2008 for business management and revenue collection. According to (11) the implementation of EFD automated system increased the number of revenue collections and so easies the process of preparing tax returns. Results from the study signals challenges of implementing EFD machines being the purchasing and maintenance cost of the devices, inexperienced customer support employees and the inability of users to correct errors. The researcher is, however, focusing only on challenges that business operators are facing rather than the Revenue Authority.

The study done by (12) investigated factors influencing implementation and utilization of EFD machine in Kenya by Small and Medium Enterprises. The study revealed that higher purchasing, installation, maintenance and annual checkup cost, poor quality of service offered by EFD suppliers and inconsistency in business classification influenced traders to evade tax. It was moreover evidenced that, EFD cumbersome when dealing with small transactions. To promote compliance and hence reduce the problem of tax evasion, the study proposes regular training and enforcement of tax law among traders to be increased. Thus, from the solutions proposed by the scholar, none of them touches technological improvement of the EFD machine and/or EFD Management System.

In March 2014, Malawi Revenue Authority (MRA) rolled out EFD system to replace the manual receipt system. As in other countries, MRA is facing various challenges in the implementation and administration of the 
EFD system. A paper done by (13) uncovers a number of challenges that hinder smooth deployment, in such ways as resistance from taxpayers, few taxpayers using the device, falsification of sales value, and insufficient number of EFD supply. The researcher furthermore proposes sanctions, penalties, stronger legal standings to offenders of tax evasion and improvement of ICT infrastructures as measures to combat tax evasion. Though the scholar suggests improvements in ICT infrastructure but didn't specify where and how should the ICT infrastructures be improved.

It was earmarked that, most of the works of literature are far more addressing challenges that EFD users are facing than challenges that revenue authorities are encountering. While the few that favors revenue authorities such that of (11) and (13) are proposing a solution that touch policy, law, education to users, purchasing price and maintenance cost of the machines but none of them are talking about the weakness of the EFD machines and EFD Management System.

According to IMF working paper prepared by (14), fiscal devices alone cannot stand as a "Silver Bullet" of tax administration; rather other technological improvements need to be considered. Therefore, this study suggests developing and embedding Stock Tracking Module into EFD Management System that will enhance the comparison between business stock records and sales return so as to identify tax evaders.

\section{MATERIAL AND METHODS}

The study was conducted in Kilimanjaro and Arusha, the two regions of Tanzania. Both regions are located in the northern part of Tanzania. The regions conduct many businesses but human drug trading was selected. Therefore, the target groups were TRA systems analysts, EFD unit officers, and drug traders. The motive for selecting drug business is the fact that human health is considered to be a priority; therefore, the same system could later be used by other regulatory authorities such as Tanzania Bureau of Standards (TBS) and Tanzania Food and Drugs Authority (TFDA) to track expired and fake drugs in the market. Kilimanjaro and Arusha regions were selected because they have a large number of drug traders who own EFD machines.

\section{A. Sample Size and Sampling Technique}

The study used a total number of 47 respondents who were clustered into three groups namely: drug traders, systems analysts and tax officers. To increase the degree of participation, 36 respondents from the first group were randomly selected from 18 different drug shops based on the factor that the pharmaceutical shop uses both an IT system to store drug records and EFD machines to print a receipt. Drug traders were involved to get information on drug acquisition, storage, and selling procedures. In the second and third group, a purposeful sampling technique was used in selecting a sample of system analysts and tax officers. System analysts were involved in the study to understand how the current system operates while tax officers to learn procedures used in tax collection and estimation process, and how to deal with tax evaders. Since each region of Tanzania contains 2 system analysts and 4 tax officers, 4 system analysts were selected in the second group and 7 tax officers out of 8 from the third group were available during the study.

\section{B. Data Collection Methods}

Data collection in the stipulated areas of study was done in the period of February to April 15, 2019. The process involved several data collection techniques in such as questionnaire, interview, observation, and roleplaying.

Questionnaire: Questionnaires were used to gather data from drug traders. They were structured into multiple choices questions, close-ended questions, ranking, scaled, and open-ended questions. Questionnaire for drug traders was set to acquire information about stock storage, the flow of drug stock from manufacturers to retailers and also their experience in using EFD machines.

Structured interview: Guided interview questions were posed to systems analysts and tax officers to collect information about their experience on how they manage and operate EFDMS, and how data exchange between EFD machines to EFDMS is done. Furthermore, the study also investigated whether embedding STM into EFD machines and EFDMS will improve tax collection.

Role-playing \& Observation: On data collection process we participated in selling and buying several items. The main aim was to understand inside-out how EFD machines work in daily business transactions and as well as how information exchange takes place between EFD machines and EFDMS.

\section{RESUlTS}

\section{A. Description of the Current System}

The interviews and questionnaires administered to TRA officials and traders were done to get knowledge on how EFD machines and EFDMS are currently working for the purpose of developing an improved one. The ongoing study uncovers numerous system weaknesses that are used by traders to evade tax. It was observed that using the current EFDMS traders are able to evade tax without being detected in such ways as under declaration of sales, avoid using EFD machine, use fake EFD machine, overestimate of expenses, division of business and conducting business in unknown areas.

Fig.1. indicates the techniques used by traders to evade tax such that $37.8 \%$ of the respondents identified underdeclaration of sales as the main technique followed by avoidance of EFD machine at $21.6 \%$, meaning that a lot of revenues are lost due to underpriced sales and avoidance of EFD machine. It was further noticed that division of business and the use of unknown areas are the two emerging techniques which are not yet popular as they smash $10.8 \%$ and $5.4 \%$ respectively on the figure.

It was further revealed that TRA had no control over traders stock, therefore tax estimation is done by refer 
ring to sales reports submitted by traders whose their loyalty is questionable.

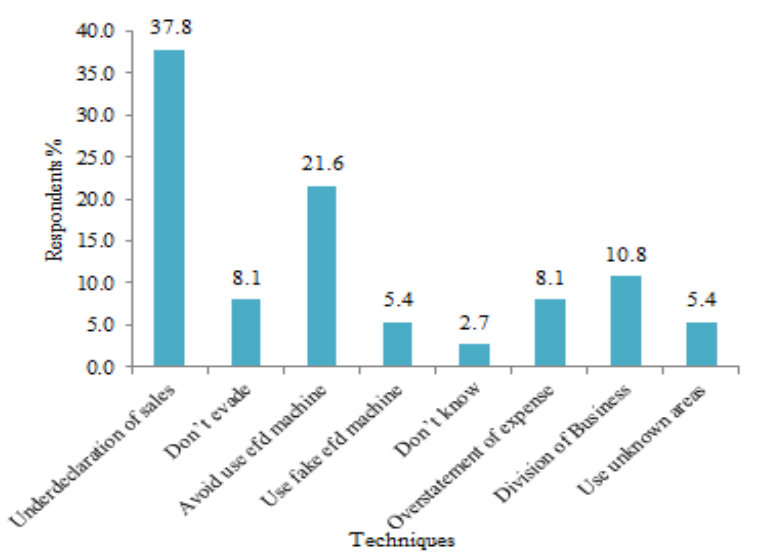

Fig.1. Techniques for Tax Evasion

Following the weaknesses pointed out by TRA respondents, $54.5 \%$ ranked the efficiency of the current system in collecting tax to be between $50 \%-75 \%$ which confirm that the current system needs some improvement. Fig.2. provides more details on such.

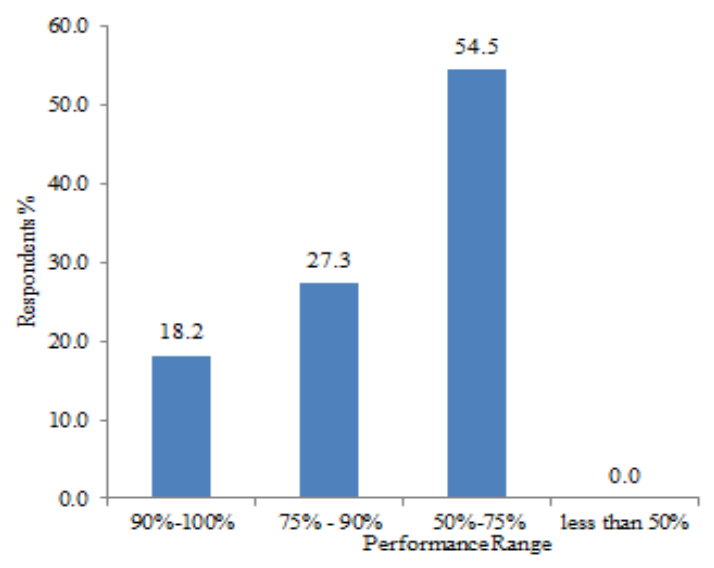

Fig.2. EFDMS Efficiency in Collecting Tax

Majority of the respondents confirmed that by embedding STM into EFD machines and EFDMS will have a positive impact on mitigating tax evasion in various ways as indicated in Fig. 3.

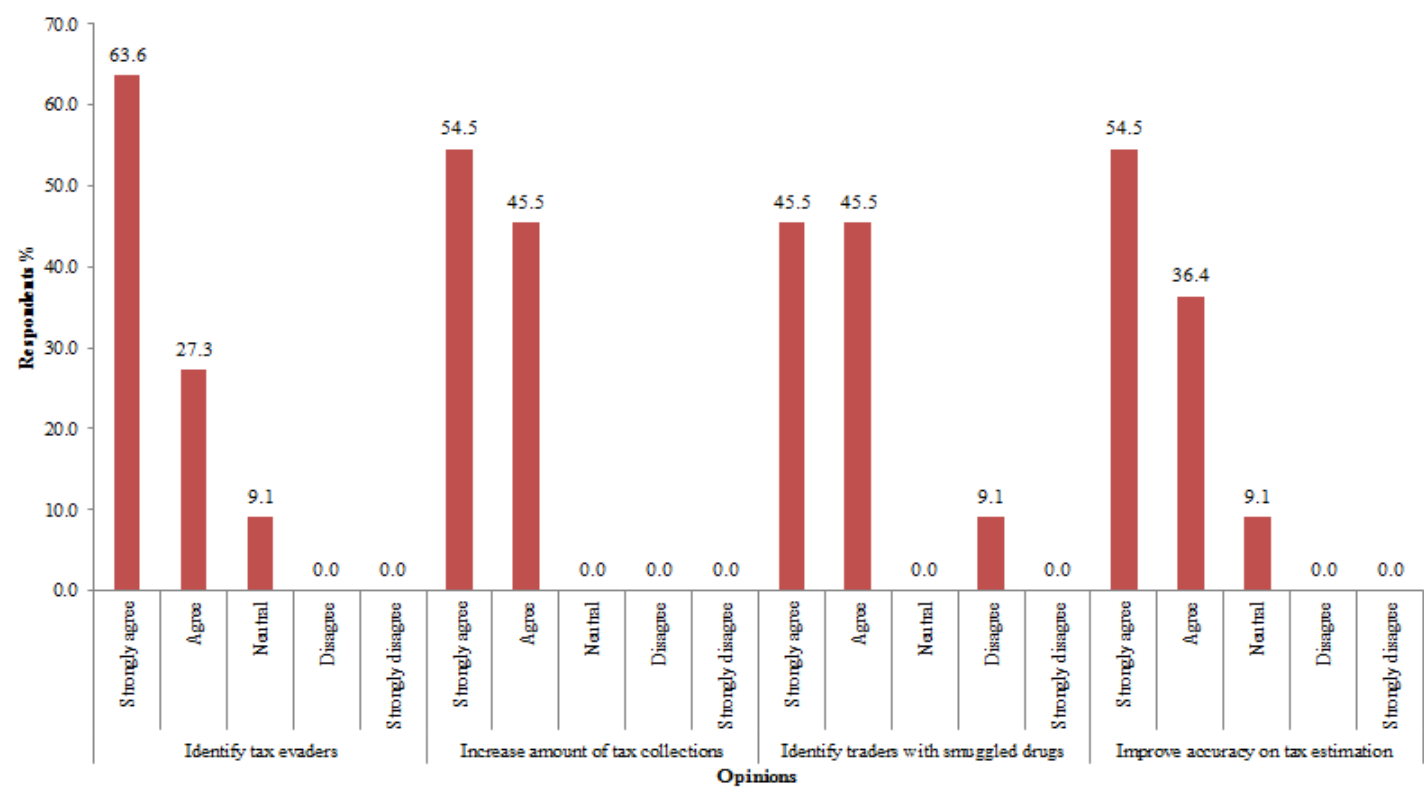

Fig.3. Respondents Opinion on Impact of Embedding STM into EFDMS

\section{B. Proposed System}

This study outlines functional and non-functional requirements for the development of improved Electronic FDMS with STM embedded. Functional requirements will present the contribution of STM to EFDMS while non-functional requirements will describe the qualities of the proposed system.

\section{Functional Requirements}

a) The embedded module must be able to capture stock source

b) The module must track stock flow between traders c) The module must set an estimated price per unit item

d) The proposed module must produce a report on traders stock

e) Produce a report on traders daily sales

f) Generate a comparison summary between traders stock records and sales

g) Issue alert on possible tax evaders

h) Generate projection on the amount of tax to be collected

i) Produce a summary report on total tax collected and evaded

j) A trader must be able to view cleared and outstanding amount of tax 


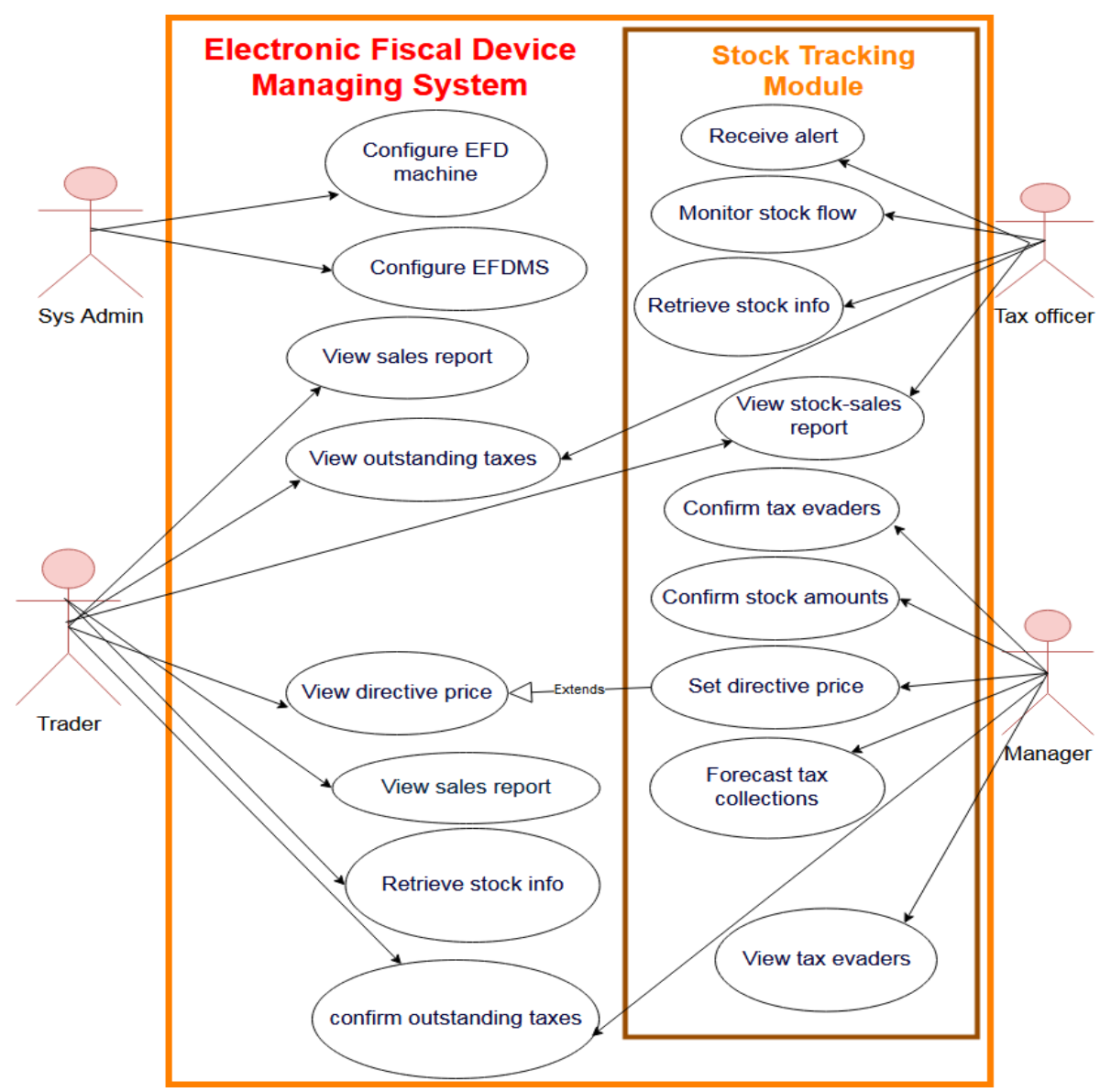

Fig.4. Use Case Diagram for the EFDMS with STM Embedded

Table 1. Functional requirements description for STM

\begin{tabular}{|l|l|l|}
\hline SS/n & Requirement & Description \\
\hline 1 & Monitor stock flow & $\begin{array}{l}\text { The module will enable tax officer to keep track of stock flow from } \\
\text { the manufacturer/importer all the way down to the retailer }\end{array}$ \\
\hline 2 & Receive stock information & $\begin{array}{l}\text { Tax officer will be able to retrieve initial stock amount entered the } \\
\text { market }\end{array}$ \\
\hline 3 & View stock-sales report & $\begin{array}{l}\text { The module will generate a summary report showing the compari- } \\
\text { son between stock flow and sales report submitted }\end{array}$ \\
\hline 4 & Receive alert & The module will alert tax officer of possible tax evader \\
\hline 5 & View outstanding taxes & $\begin{array}{l}\text { The system will produce tax information for each trader based on } \\
\text { the stock sold }\end{array}$ \\
\hline 6 & Set directive price & $\begin{array}{l}\text { Manager will be able to set directive price each stock item. This } \\
\text { price will be used to compute the amount of tax to be paid by a } \\
\text { trader }\end{array}$ \\
\hline 7 & $\begin{array}{l}\text { Based on the comparison between stock information and sales re- } \\
\text { port manager will be able to confirm tax evaders }\end{array}$ \\
\hline 8 & Confirm tax evader & $\begin{array}{l}\text { The module will enable the tax officer to confirm the amount of } \\
\text { stock received and sold in a particular range of period }\end{array}$ \\
\hline 9 & Confirm stock amount & $\begin{array}{l}\text { The manager will be able to forecast the amount of tax to be collect- } \\
\text { ed in certain business area }\end{array}$ \\
\hline 10 & Forecast tax collections & The system will generate a list of possible tax evaders \\
\hline
\end{tabular}




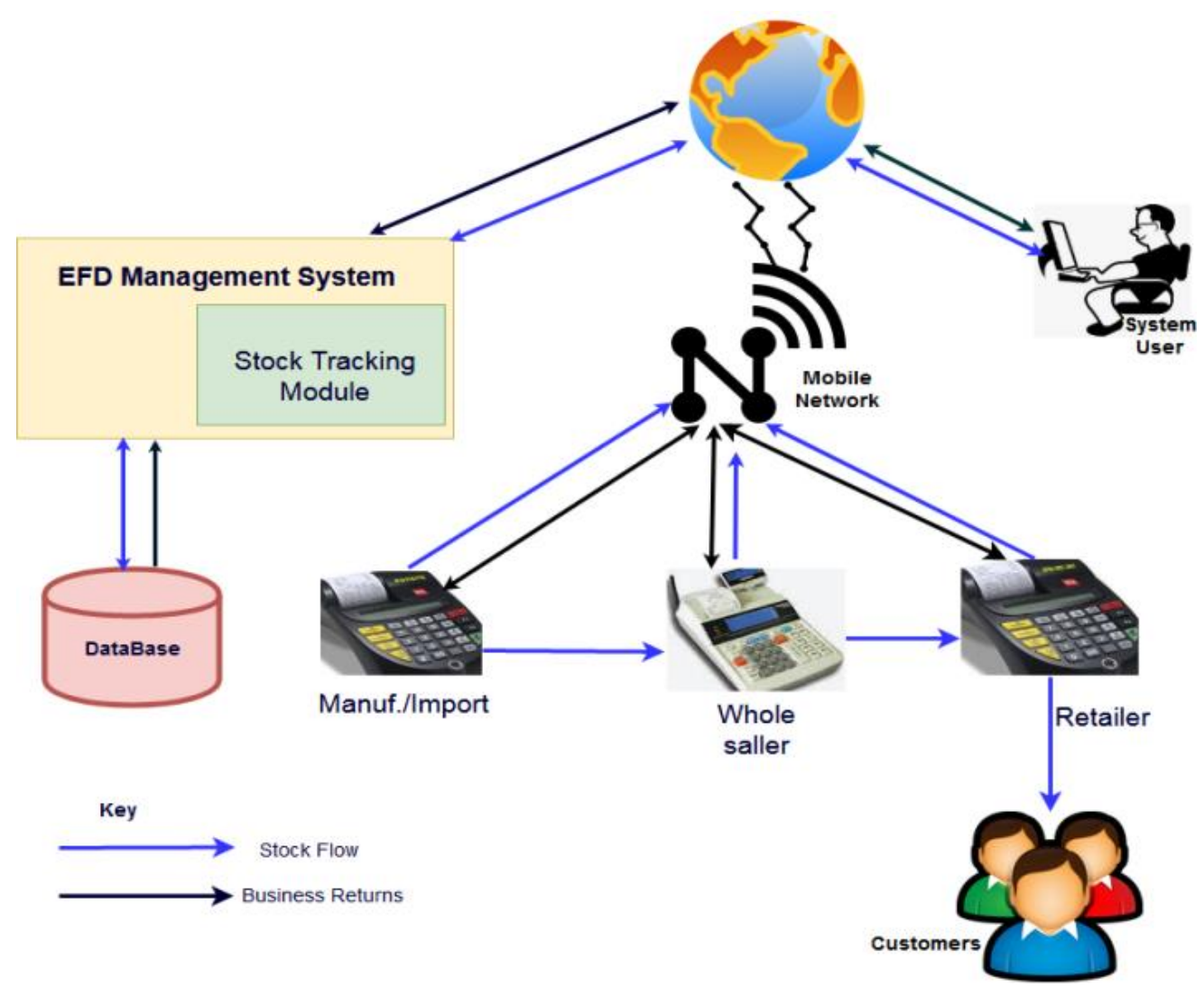

Fig.5. A Conceptual Framework for EFDMS with STM

\section{Non-functional Requirements}

System Scalability: While reviewing the existing system and gathering requirements for the development of the stock tracking module we have earmarked several points of benefit to other regulatory organs if their systems will be linked with the proposed system. The system can appropriately enable Tanzania Food and Drugs Authority (TFDA) to identify and locate traders owning fake and expired drugs or food products in the market as among of the attributes captured by the module being the manufacturing and expiry date of the stock. Not only that but, the system can be linked with the Tanzania Bureau of Standards (TBS) database to tell the existence of unapproved products in the market.

System Security: Since stock details are a crucial attribute for the tax calculation, the security of stock tracking module will carefully be considered during development. Each user of the system will be provided with login credentials whereby sessions will be generated for every successful login and terminated upon logout. To make the security more robust, the system will have different access levels. Again in each access level, the system will be implemented in a role-based fashion, such that, a user of a certain access level can perform only the assigned tasks of that level.

\section{E. Database Schema and App Design}

Fig.6. represent database schema of the system to be developed. Database tables are categorized into: User and Role management tables - the tables that contain details for user login, access levels, personal information, roles and privileges; Stock and Sales tables - the tables that contain information about stock flow and sales return; Traders, EFD machine and Tax tables - the tables that store information concerning registration of traders, EFD machines, financial years and various types of taxes charged by TRA. 


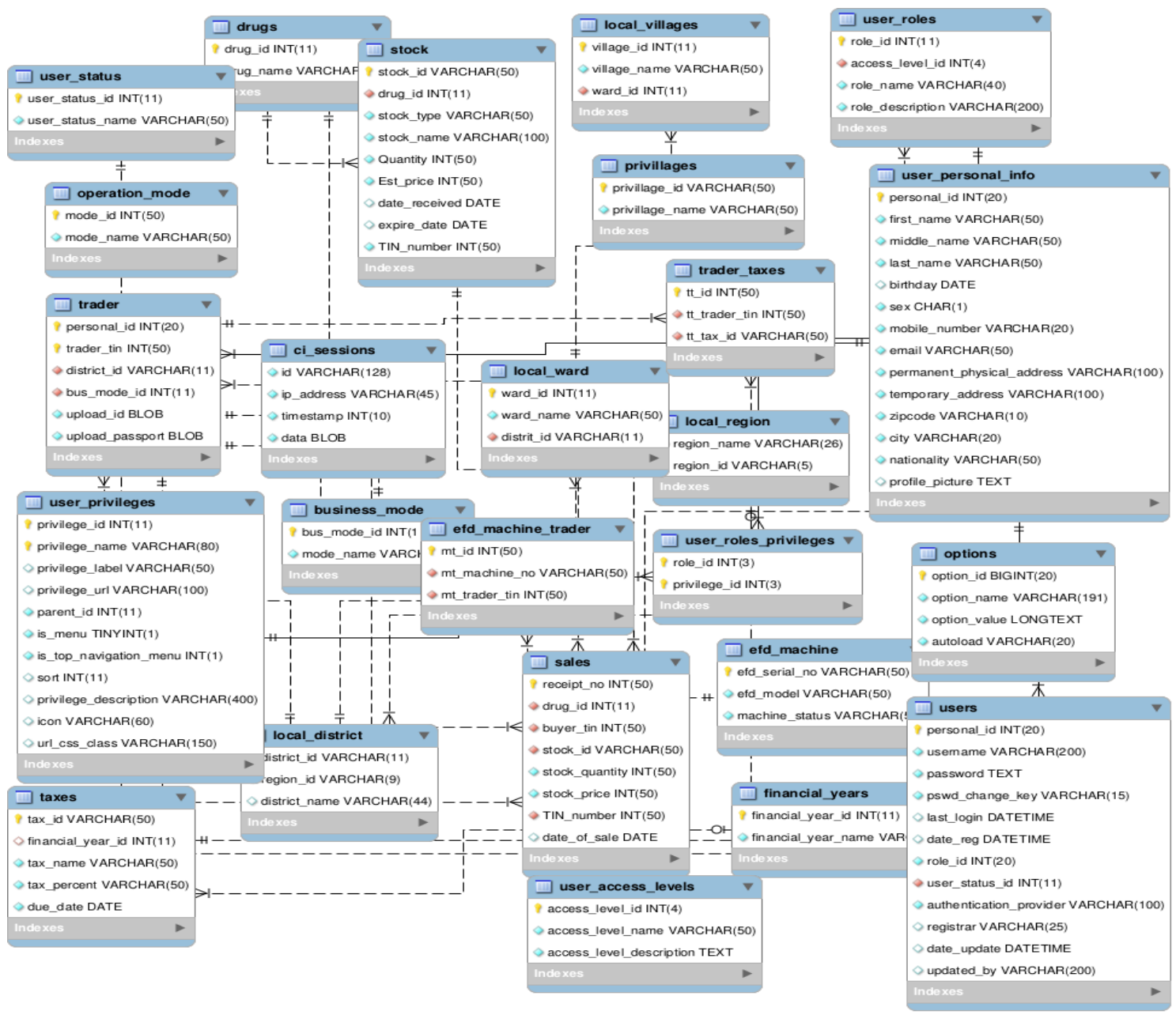

Fig.6. EFDMS Database Schema

Fig.7, Fig.8, Fig.9, and Fig.10, are some of EFD machine application layouts where by: fig.7, is the EFD Machine application main screen design - showing six operation modes of the EFD machine, fig. 8 , is the Registration Mode layout that provide room for trader to sale an item, fig.9, is one of the Programming Mode layouts that provide interface for fiscalization of the device, while fig.10, is also a Programming mode layout that provides room for a trader to register business items in the EFD machine.

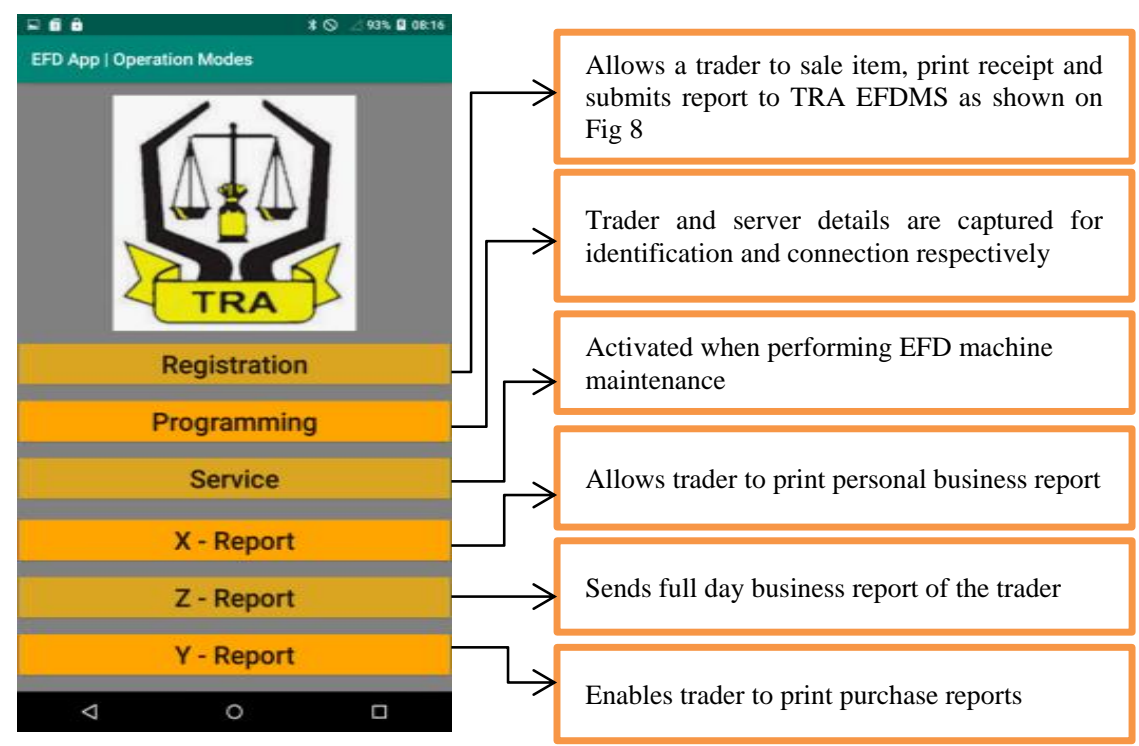

Fig.7. EFD Machine Application Main Screen Design 


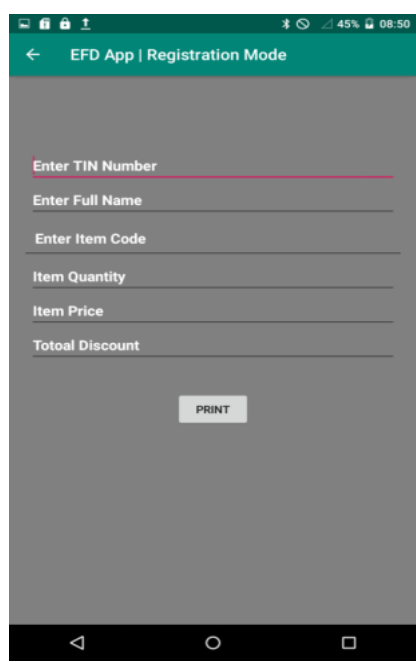

Fig.8. Registration Mode Layout

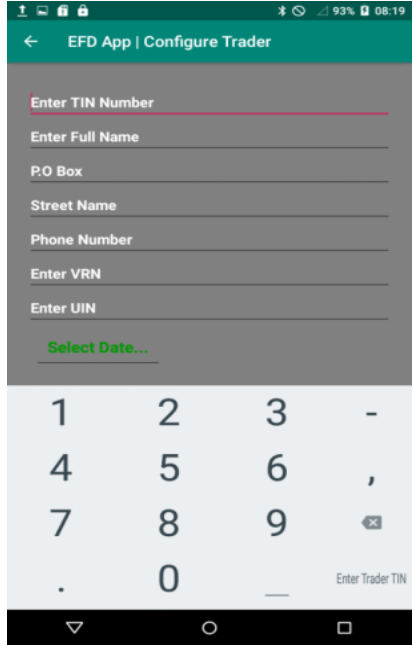

Fig.9.Trader Registration Layout

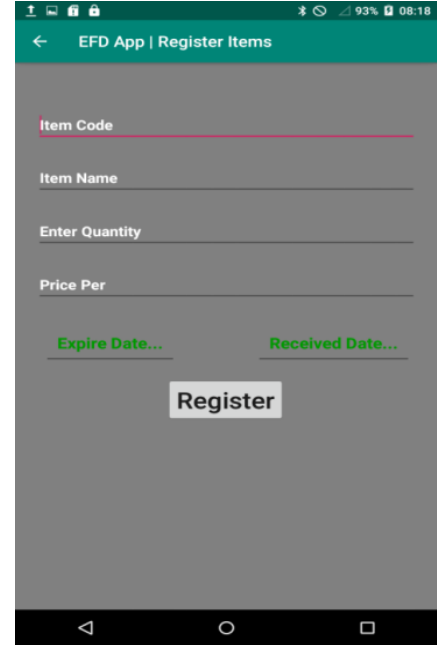

Fig.10.Items Registration Layout

\section{DisCUSSION}

The findings of this study entail several weaknesses that the current EFDMS is having, which includes inability to identify underpriced sales, overstatement of expenses, division of a business, the use of unknown areas, forged receipts and transactions that receipts were not issued at all. Tax estimation is done by looking at the sales report submitted by traders; however, EFDMS cannot verify the correctness of such reports which results in loss of government revenues. Furthermore, the study observed that neither stock information recorded nor directive price is set by the system which is important parameters to verify sales report submitted.

Therefore, to deal with the pointed weaknesses this study proposes the development of the Stock Tracking Module which will be embedded into the current EFDMS. The system will capture initial stock from importer or manufacturer (stock origins) and sale to suppliers or whole sellers who may also sell to fellow wholesellers/suppliers and finally to retailers who will finally sale to consumers. On selling, the system will decrement the seller's stock and increments buyer's stock and the process will keep on repeating along the business chain such that every commodity sold will be seen on the system. The system will also provide room for a systems administrator to set directive price (estimate price) for each commodity such that the system will now be able to compare sales return submitted by traders and identify whether there is under-priced commodities or sales done without issuing a receipt.

Results of the study suggest that by embedding the module will have an impact on mitigating tax evasion in such a way that avoidance of EFD machine, underpriced and forged transactions will be detected by the system automatically. The process will also give TRA knowledge on where and when the stock was acquired and whether is depleted or otherwise. Not only that but it will reduce the workload to a tax officer who visits one business after another for tax inspection.

With the forecasted solution the system will generate various reports to both traders and TRA officials. To ac- complish the proposed solution the researcher will design, develop and embed STM into current EFDMS whereby various software, programming languages, and tools will be involved.

\section{CONCLUSION}

This paper has reviewed both Electronic Fiscal Device Management System, EFD machine and then analyzed requirements for the development of Stock Tracking Module for the purpose of mitigating tax evasion to drug traders in Tanzania. Various techniques used by traders to evade tax was uncovered by the study such as; Underpricing of sales, Avoid using EFD machines, Use fake EFD machines to print business receipts, Division of business, Overestimate of expenses and running a business in unknown areas. The study also confirms that the proposed solution if adopted by TRA will increase EFDMS efficiency and hence increase revenue collections.

Moreover, the proposed solution will help to reduce manual work and number of tax officers needed for tax inspection and lastly the process of tax estimation will be more open and accurate hence reducing complains among traders and government at large. However in future, more research is open to integrate EFDMS database with Tanzania Food and Drugs Authority (TFDA) and Tanzania Bureau of Standards (TBS) databases to identify and locate traders owning fake and expired drugs or food products in the market. Not only that but this study opens the door to other scholars to research on incorporating bar code reader into the EFD machine to easy the process of filling in commodity information during selling and printing receipts.

\section{REFERENCES}

[1] Matsaganis M, Leventi C. Distributive Effects of the Crisis and Austerity in seven EU Countries. Work Pap Improv Poverty Soc Policy Innov. 2014;(14/04).

[2] Tenidou E, Valsamidis S, Petasakis I, Mandilas A. Elenxis, an Effective Tool for the War Against Tax Avoidance and Evasion. Procedia Econ Financ [Internet]. 
2015;33(15):303-12. Available from: http://linkinghub.elsevier.com/retrieve/pii/S22125671150 17141

[3] OECD. Technology Tools to Tackle Tax Evasion and Tax Fraud. Oecd [Internet]. 2017; Available from: http://www.oecd.org/tax/crime/technology-tools-totackle-tax-evasion-and-tax-fraud.htm

[4] Weru JM, Kamaara MW, Weru A j. Impact of Strategic Change: Introduction of Electronic Tax Register for Enhancement of Tax Collection At Kenya Revenue Authority. Internatinal Jouranl Econ Financ. 2013;1(5):113.

[5] URT TUR of T. The Value Added Tax Act, 2014. 2014;(10).

[6] Chege A, Kiragu N, Lagat C, Muthoni G. Effect of Electronic Fiscal Devices on VAT Collection in Tanzania: A Case of Tanzania Revenue Authority. Eur J Bus Manag. 2015;7(33):2222-839.

[7] Shabu M. MANAGING TAX RISK: Challenges of EFD receipts. The Citizen [Internet]. 2017 Aug 24; Available from:

http://www.thecitizen.co.tz/magazine/businessweek/MAN AGING-TAX-RISK--Challenges-of-EFDreceipts/1843772-4069618-wht0h7z/index.html

[8] URT TUR of T. The Income Tax Act,Cap. 332, Revised Edition. 2008;1-130.

[9] Ikasu EJ. Assessment of Challenges Facing the Implementation of Electronic Fiscal Devices ( EFDs ) in Revenue Collection in Tanzania. 2014;5(3):1-8.

[10] Delphine C. Challenges Facing The Adoption Of Electronic Fiscal Devices (Efds) In Revenue Collection: A Case Of Morogoro Municipality, Tanzania. 2017;

[11] Mohammed Hk. Challenges Of Electronics Tax Register Machine ( Etrs ) To Challenges Of Electronics Tax Register Machine ( Etrs ) To. 2015;(October).

[12] Nyareru Jo, Kibati P. Factors Influencing Implementation And Utilization Of Electronic Tax Registers By Small And Medium Enterprises In Nakuru Town, Kenya. 2017;V(12):726-72.

[13] Lapukeni AF. An Overview Of The Use Of Electronic Fiscal Device In VAT Collection In Malawi Presentation Made At The Third Africa for Results Forum - AfriK4R : 2017;(July 2016).
[14] Sachlos E, Auguste D. Electronic Fiscal Devices (EFDs) An Empirical Study of their Impact on Taxpayer Compliance and Administrative Efficiency. Biomaterials. 2008;29(34):4471-80.

\section{Authors' Profiles}

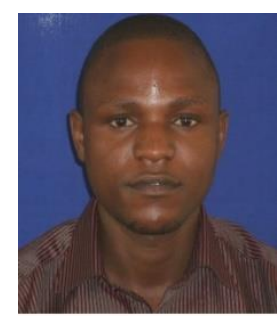

Paul E. Shao received his BSc in Computer Science from the St. Augustine University of Tanzania, Tanzania, in 2011. Currently, he is at the Nelson Mandela African Institution of Science and Technology (NM-AIST) pursuing Master's Degree in Information and Communications Science and Engineering (ICSE). Currently he is working with Mwenge Catholic University in Kilimanjaro, Tanzania as a lecturer. He has experience in systems development and networking. His research interests include system development, tracking systems, and mobile application development.

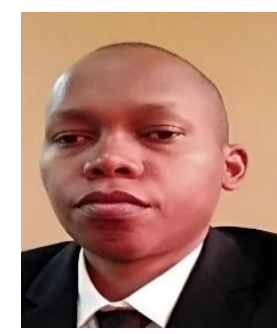

Dr. Mussa Ally Dida is a Lecturer at Nelson Mandela African Institution of Science and Technology (NM-AIST). $\mathrm{He}$ acquired his B.Sc. in Computer Engineering and Information Technology from University of Dar es Salaam (UDSM), M.Sc. in Telecommunication Engineering from University of Dodoma (UDOM) 2008 and 2011 respectively and a Ph.D. in Information and Communication Engineering from Beijing Institute of Technology (BIT), Beijing, China in 2017. His research interests include signals and communication systems analysis, modeling and optimization, online system development and currently working in farmers' extension support system and private school enrollment and communication systems.

How to cite this paper: Paul E. Shao, Mussa Ally Dida, "Embedding Stock Tracking Module into Electronic Fiscal Device Machine and its Management System to Reduce Tax Evasion: A case of Tanzania", International Journal of Information Engineering and Electronic Business(IJIEEB), Vol.11, No.5, pp. 24-32, 2019. DOI: 10.5815/ijieeb.2019.05.04 